Article

\title{
Experimental and Theoretical Studies on Corrosion Inhibition of Niobium and Tantalum Surfaces by Carboxylated Graphene Oxide
}

\author{
Valbonë Mehmeti and Fetah I. Podvorica * \\ FNMS, Department of Chemistry, University of Prishtina, Prishtina 10000, Kosovo; \\ valbonamehmeti1@gmail.com \\ * Correspondence: fetah.podvorica@uni-pr.edu; Tel.: +383-44-150-615
}

Received: 16 April 2018; Accepted: 22 May 2018; Published: 25 May 2018

\begin{abstract}
The corrosion of two different metals, niobium and tantalum, in aqueous sulfuric acid solution has been studied in the presence and absence of carboxylated graphene oxide. Potentiodynamic measurements indicate that this nanomaterial inhibits corrosion due to its adsorption on the metal surfaces. The adsorbed layer of carboxylated graphene hinders two electrochemical reactions: the oxidation of the metal and the transport of metal ions from the metal to the solution but also hydrogen evolution reaction by acting as a protective barrier. The adsorption behavior at the molecular level of the carboxylated graphene oxide with respect to $\mathrm{Nb}, \mathrm{NbO}, \mathrm{Ta}$, and $\mathrm{TaO}$ (111) surfaces is also investigated using Molecular Dynamic and Monte Carlo calculations.
\end{abstract}

Keywords: niobium; tantalum; carboxylated graphene oxide; nanomaterials; corrosion inhibition; molecular dynamics; Monte Carlo calculation

\section{Introduction}

In general, metals are prone to oxidation when exposed to different aggressive solutions in the course of industrial cleaning or other diverse treatments (acid pickling, descaling and cleaning). Although the use of paints and polymers offers a simple approach to decrease the effect of corroding species on the surface, the major drawbacks of this method are the weak interactions among the metal surface and the coating layer so the physical organic barrier is deteriorated after a short time of exposure [1]. The widespread method of the protection of metals against corrosion remains the use of inhibitors molecules [2-4]. These moieties when added at relatively small concentrations in the corrosive media where the metal is exposed can interact with its surface, forming an organic coating and therefore decreasing the corrosion rate. Other approaches for corrosion inhibition rely on the use of surface modification strategies through the formation SAM's (Self Assembled Monolayers) using phosphonic acids [5,6], silanes, aryl diazonium salts [7], etc. Graphene is considered as one of the most important classes of modern materials-nanomaterials [8], which are extensively explored for use in different fields of science from drug delivery [9] to photovoltaics [10]; however, graphene remains almost unexplored towards applications aimed at the corrosion inhibition of materials. Only limited scientific research that uses graphene nanomaterials is devoted to corrosion studies [11-13], and to our knowledge there is no reported study on the use of carboxylated graphene oxide (GO-COOH) as a corrosion inhibitor. The production of nanomaterials is steadily increasing [14,15] using low-cost, abundant natural materials [16]; therefore, the future use of nanomaterials in corrosion protection is promising.

Quantum chemical methods are widely employed for the study of the physico-chemical properties of the inhibitors in order to understand at the molecular level their interaction with the 
metal surface $[1,4,17,18]$. Density Functional Theory (DFT), as a powerful technique for performing calculations on many bodied systems, permits the correlation between the adsorption ability of the inhibitor molecule on the metal surface and its electron donating tendency that is expressed by the value of $\mathrm{E}_{\mathrm{HOMO}}$. Higher values for this orbital suggest an increasing donor-acceptor interaction between the inhibitor molecule and the vacant d-orbitals of the metal surface atoms $[19,20]$. DFT calculations also make possible the estimation of other parameters like the dipole moment, electronegativity and ionization potential energy [21]. For example, the inhibitor efficiency increases when the metal surface is covered with higher dipole moment molecules due to the electrostatic interaction between the charged metal surface and charged centers of molecules [22]. Molecular dynamics simulation provides more insight into the corrosion inhibition mechanism and the different interactions at the interface inhibitor-metal surface [23]. However, for larger systems, these methods are computationally costly to employ.

In this work, molecular dynamics [24,25] and Monte Carlo [26] simulation are used to evaluate the interaction between the $\mathrm{Nb}(111), \mathrm{NbO}(111), \mathrm{Ta}(111)$ and $\mathrm{TaO}$ (111) and carboxylated graphene.

\section{Materials and Methods}

\subsection{Experimental Section}

Carboxyl Graphene (Dispersion, $5 \mathrm{mg} / \mathrm{mL}$, ACS Material, Pasadena, CA, USA) dissolved in aqueous solution of $\mathrm{H}_{2} \mathrm{SO}_{4}$ at $\mathrm{c}=0.1 \mathrm{~mol} / \mathrm{dm}^{3}$ was used at a concentration of $2.5 \times 10^{-2} \mathrm{mg} / \mathrm{mL}$. The GO-COOH was well dispersed. For the electrochemical measurements, the electrodes were prepared by embedding a niobium wire $(d=1 \mathrm{~mm}, l=10 \mathrm{~mm}$, (annealed), 99.8\% (metals basis), Alfa Aesar ${ }^{\circledR}$, CAS: 7440-03-1, Karlsruhe, Germany) and tantalum wire $(d=0.5 \mathrm{~mm}, l=10 \mathrm{~mm}$, (annealed), 99.95\% (metals basis), Alfa Aesar ${ }^{\circledR}$, CAS: 7440-25-7, Karlsruhe, Germany) inside a Teflon ${ }^{\circledR}$ $\left(d=1 \mathrm{~cm}, l=6 \mathrm{~cm}\right.$, Alfa Aesar ${ }^{\circledR}$, Karlsruhe, Germany) tube with epoxy resin. Prior to use, the electrodes were polished on silicon carbide abrasive paper (medium grain diameter 6.5-15.3 microns), then on a (DP-Nap) cloth with an aluminium oxide ( 0.3 micron particle size) suspension, and then the electrodes were washed and sonicated in water.

Sulphuric acid 97\%, pro analysis, MERCK, UN-No.1830 (Darmstadt, Germany) is used as the electrolyte for the potentiodynamic measurements. Its concentration in whole measurements was $0.1 \mathrm{~mol} / \mathrm{dm}^{3}$.

The electrodes were made of commercial niobium $(d=1 \mathrm{~mm})$ and tantalum $(d=0.5 \mathrm{~mm})$ wires. Prior to electrochemical measurements, metal surfaces were mechanically polished with emery paper, cleaned with distilled water and degreased in ethanol, washed with distilled water and finally dried in air. The electrochemical studies and linear sweep voltammetry (LSV) were performed using an Autolab potentiostat (Metrohm Autolab, Utrecht, Netherland) and employing a three-electrode cell assembly. A saturated calomel electrode (SCE) and platinum electrode were used as reference and auxiliary electrodes, respectively. All solutions were prepared from analytic grade chemicals and bidistilled water. The metal electrodes were allowed to stabilize their open circuit potential (OCP) until the potential stabilization criteria of $\mathrm{dE} / \mathrm{dt}$ limit $10^{-6} \mathrm{~V} / \mathrm{s}$ is reached. Potentiodynamic polarization was carried out by scanning the potential $\pm 250 \mathrm{mV}$ from the evaluated OCP using a scan rate of $1 \mathrm{mV} \mathrm{s}^{-1}$. Polarization experiments were carried out using a potentiostat from Eco Chemie BV, the Netherlands, Autolab PGSTAT128N (Metrohm, Utrecht, The Netherland), and the obtained data were analyzed with Autolab software (NOVA 2.0.1, Metrohm, Utrecht, Netherland).

\subsection{Monte Carlo Simulations}

Adsorption Locator module in Materials Studio 7.0 was used to build Nb (111), NbO (111), $\mathrm{Ta}$ (111) and $\mathrm{TaO}$ (111). The carboxylated graphene model (Figure 1) was built using Avogadro software (version no.1.0.1, Softonic, Barcelona, Spain) and was optimized using Universal force field (energy convergence tolerance of $2 \times 10^{-5} \mathrm{kcal} / \mathrm{mol}$, force convergence tolerance of 
$0.001 \mathrm{kcal} / \mathrm{mol} / \mathrm{A})$. The molecular dynamic simulations of the interaction between the GO-COOH studied as inhibitor and the surfaces were carried out in the simulation box with corresponding dimensions: $[\mathrm{Nb}(111)-28.00 \AA \times 28.00 \AA \times 5.47 \AA ; \mathrm{NbO}(111)-28.32 \AA \times 26.79 \AA \times 6.31 \AA$; Ta (111) - 28.02 $\AA 28.02 \AA \times 4.67 \AA ; \mathrm{TaO}(111)-31.26 \AA \times 31.26 \AA \times 6.63 \AA$ using periodic boundary conditions with a of $20 \AA$ vacuum along the C-axis. The solvent (water) effect was simulated by loading 50 water molecules (geometrically optimized using Universal forcefield) into the simulation box together with the studied molecules (using the same optimization algorithm). The Metropolis Monte Carlo method was used to evaluate the adsorption configurations (Universal, force field) of the interaction between the molecule and the substrates.

\subsection{Molecular Dynamic (MD) Simulations}

The MD simulations with the Forcite Module (Materials Studio) were performed using Universal Forcefield. Prior to the use of MD simulations, the surfaces were optimized using the Smart optimization algorithm with the energy convergence criteria of $10^{-4} \mathrm{kcal} / \mathrm{mol}$ and force criteria of $5 \times 10^{-3} \mathrm{kcal} / \mathrm{mol} / \AA$. The atom charges were assigned using the QEq method with the atom-based electrostatic and Van der Waals summation method (truncation: cubic spline, cutoff distance $15.5 \AA$, and spline width $1 \AA$ ). The optimized structure of GO-COOH was added to the optimized slab surface along the perpendicular directions. A "vacuum layer" with a height of $50 \AA$ was placed upon the surface with PBC (periodic boundary conditions). The MD was conducted using an NVT (constant-temperature, constant-volume) canonical ensemble at $298 \mathrm{~K}$. The time step for MD was $1 \mathrm{fs}$ with a total simulation time of $300 \mathrm{ps}\left(3 \times 10^{5}\right.$ steps). The system temperature was maintained using a Berendsen Thermostat ( 0.1 ps decay constant). For the data analysis, 300 ps of trajectory frames were used.

\subsection{Adsorption Energy and Radial Distribution Function}

The adsorption energy was calculated using the following equation:

$$
\mathrm{E}_{\text {adsorption }}=\mathrm{E}_{\text {total }}-\left(\mathrm{E}_{\text {surf. }}+\mathrm{E}_{\mathrm{GO}-\mathrm{COOH}}\right) / \text { slab area }
$$

The radial distribution function (RDF) $[22,23,27,28]$ defines the probability of finding adsorbate molecules at distance $r$ from the surface atoms of the slab models. It was calculated as follows:

$$
\mathrm{g}(\mathrm{r})=(\mathrm{n}(\mathrm{r})) / 2 \pi \mathrm{r} \Delta \mathrm{r} \rho
$$

where $\mathrm{r}(\mathrm{A})$ is the given distance from surface atoms from the slab, $\mathrm{n}(\mathrm{r})$ is a time-averaged number of atoms in the area of $r \pm \Delta r, \rho$ is the number density of the system.

\section{Results and Discussion}

\subsection{Potentiodynamic Polarization}

Polarization plots obtained for the $\mathrm{Nb}$ and Ta electrodes in a $0.1 \mathrm{M} \mathrm{H}_{2} \mathrm{SO}_{4}$ aqueous solution in the presence and the absence of carboxylated graphene oxide are shown in Figure 1a,b.

Potentiodynamic measurements, in the case of the $\mathrm{Ta}$ and $\mathrm{Nb}$ bare electrodes, showed a fast increase of the anodic current, after the corrosion potential. In both cases, there is an active dissolution of tantalum and niobium due to the formation of $\mathrm{Ta}^{5+}$ and $\mathrm{Nb}^{5+}$ ions, respectively, which slow down around $-0.05 \mathrm{~V}$.

According to the Pourbaix diagrams for the $\mathrm{Ta}-\mathrm{H}_{2} \mathrm{O}$ and $\mathrm{Nb}-\mathrm{H}_{2} \mathrm{O}[29,30]$, in aqueous sulphuric acid solution at $25^{\circ} \mathrm{C}$ at $\mathrm{pH}$ value $>0.5$, Ta and $\mathrm{Nb}$ are oxidized to $\mathrm{Ta}_{2} \mathrm{O}_{5}$ and $\mathrm{Nb}_{2} \mathrm{O}_{5}$; therefore, the formation of passive oxide layers prevents further oxidation of metals when they are under positive potential [31,32]. 
The inhibition behavior of the GO-COOH layer is evidenced by the decreased anodic and cathodic current densities.
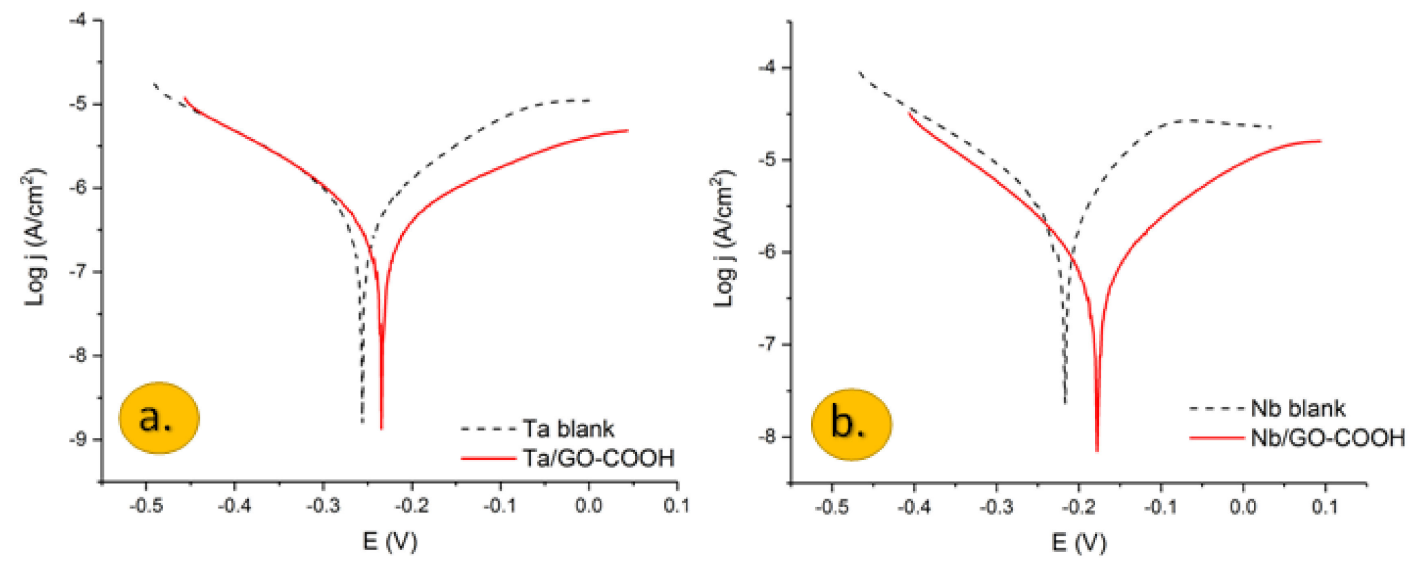

Figure 1. Semilogarithmic polarization plots of: (a) Ta and (b) $\mathrm{Nb}$ electrodes in a $0.1 \mathrm{M} \mathrm{H}_{2} \mathrm{SO}_{4}$ aqueous solution with and without the presence of 100 ppm GO-COOH. Ref. SCE. v = $1 \mathrm{mv} / \mathrm{s}$.

The kinetic electrochemical corrosion parameters, corrosion current density (Icorr), cathodic and anodic Tafel slopes and corrosion potential (Ecorr), were calculated from the extrapolation of Tafel plots, and the values are presented in Table 1.

Even though the corrosion current density decreases in the presence of GO-COOH, the corrosion potential does not change significantly in the presence of the inhibitor. The anodic Tafel slope is somewhat larger than that of the cathodic one, and the corrosion potential is slightly displaced anodically, showing that this protective barrier acts mainly as an anodic inhibitor. Graphene layers are well known for the creation of adhered coatings on metal surfaces and affect the slope of anodic and cathodic reactions and hinder the corrosion reaction due to the large specific surface area and excellent mechanical properties [11,33]. These layers may hinder the diffusion of water molecules to the electrode surface [33].

Table 1. Results of Tafel slope analysis of the polarization plots at $298 \mathrm{~K}$.

\begin{tabular}{cccccc}
\hline $\begin{array}{c}\text { Studied System } \\
\left.\text { (in 0.1 } \mathbf{~ M ~ H}_{\mathbf{2}} \mathbf{S O}_{\mathbf{4}}\right)\end{array}$ & $\mathbf{B}_{\mathbf{c}}\left(\mathbf{V ~ d e c}^{-\mathbf{1}}\right)$ & $\mathbf{B}_{\mathbf{a}}\left(\mathbf{V ~ d e c}^{-\mathbf{1}}\right)$ & $\mathbf{j}_{\text {corr }}\left(\mathbf{A c m}^{-\mathbf{2}}\right)$ & Ecorr (V/SCE) & IE (\%) \\
\hline $\mathrm{Nb}$ & 0.167 & 0.092 & $2.46 \times 10^{-6}$ & -0.205 & - \\
$\mathrm{Nb}+\mathrm{GO}-\mathrm{COOH}$ & 0.139 & 0.149 & $7.33 \times 10^{-7}$ & -0.175 & 70.22 \\
$\mathrm{Ta}$ & 0.165 & 0.131 & $5.71 \times 10^{-7}$ & -0.247 & - \\
$\mathrm{Ta}+\mathrm{GO}-\mathrm{COOH}$ & 0.145 & 0.225 & $2.05 \times 10^{-7}$ & -0.240 & 64.07 \\
\hline
\end{tabular}

The inhibition efficiency (IE) was calculated from the corrosion current density of the metal electrodes in the absence and presence of the inhibitor using the following equation: it reached $70 \%$ and $64 \%$ for $\mathrm{Nb}$ and $\mathrm{Ta}$, respectively.

$$
\operatorname{IE}(\%)=\left(\mathrm{I}_{\text {unhib }}\right)-\left(\mathrm{I}_{\text {inh }}\right) /\left(\mathrm{I}_{\text {unhib }}\right) \times 100
$$

We compared these experimental results with those of the differential simulations. The Universal force field correctly describes the $\mathrm{C}-\mathrm{C}, \mathrm{C}-\mathrm{O}$ distances in the $\mathrm{GO}-\mathrm{COOH}$ structure, Figure 2 . The bond lengths for the computed GO- $\mathrm{COOH}$ are in good agreement with the generally found experimental bond lengths and are as follows: $-\mathrm{C}=\mathrm{C}-(1.409 \AA),-\mathrm{C}=\mathrm{O}(1.22 \AA), \mathrm{C}-\mathrm{O}(\mathrm{H})(1.39 \AA)$. We have considered that all $\mathrm{COOH}$ groups were protonated due to the low $\mathrm{pH}$ value of the aqueous solution of $0.1 \mathrm{M}$ $\mathrm{H}_{2} \mathrm{SO}_{4}$ so the inhibitor is a neutral molecule and any influence of protons is assumed to be negligible. 


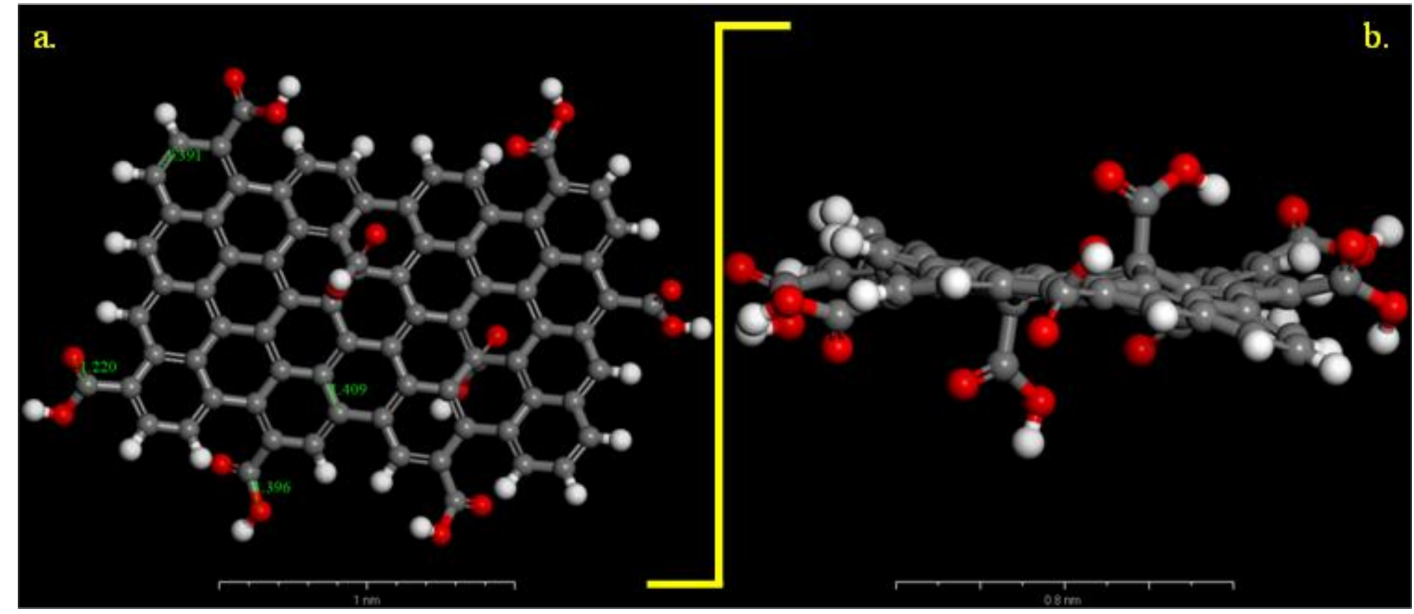

Figure 2. Optimized carboxylated graphene model (Universal forcefield): (a) on top view and (b) side view. Gray colour: $\mathrm{C}$ atoms, white colour: $\mathrm{H}$ atoms and red colour: $\mathrm{O}$ atoms.

The adsorption of GO-COOH evaluated from the Monte Carlo simulations on both surfaces exhibits many adsorptive configurations, see Figures 3 and 4. These configurations arise from different approaching paths and geometries of the GOx molecule.

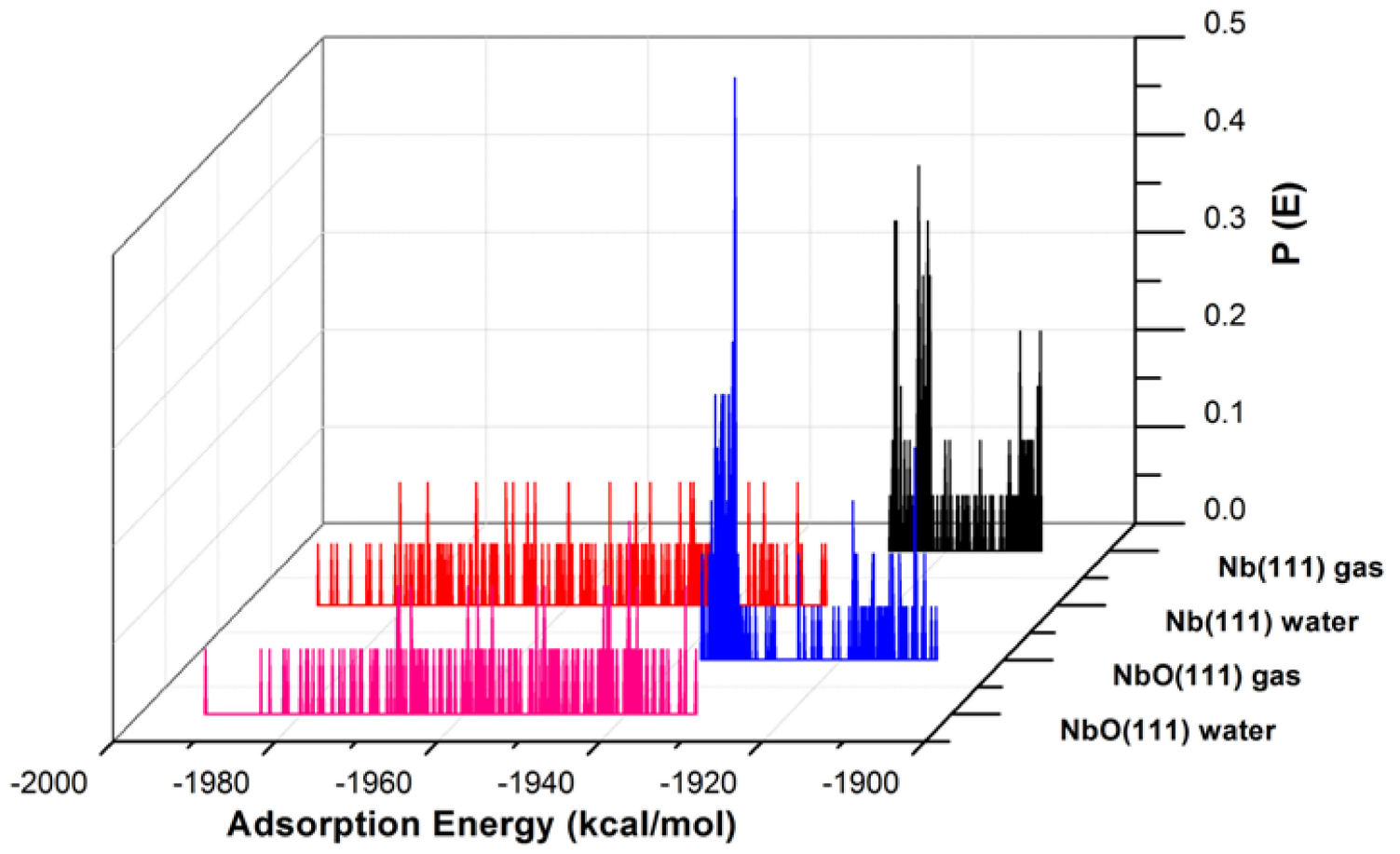

Figure 3. The adsorption energy distribution of the GO-COOH on $\mathrm{Nb}(111)$ and $\mathrm{NbO}(111)$ surfaces in the presence and absence of water. 


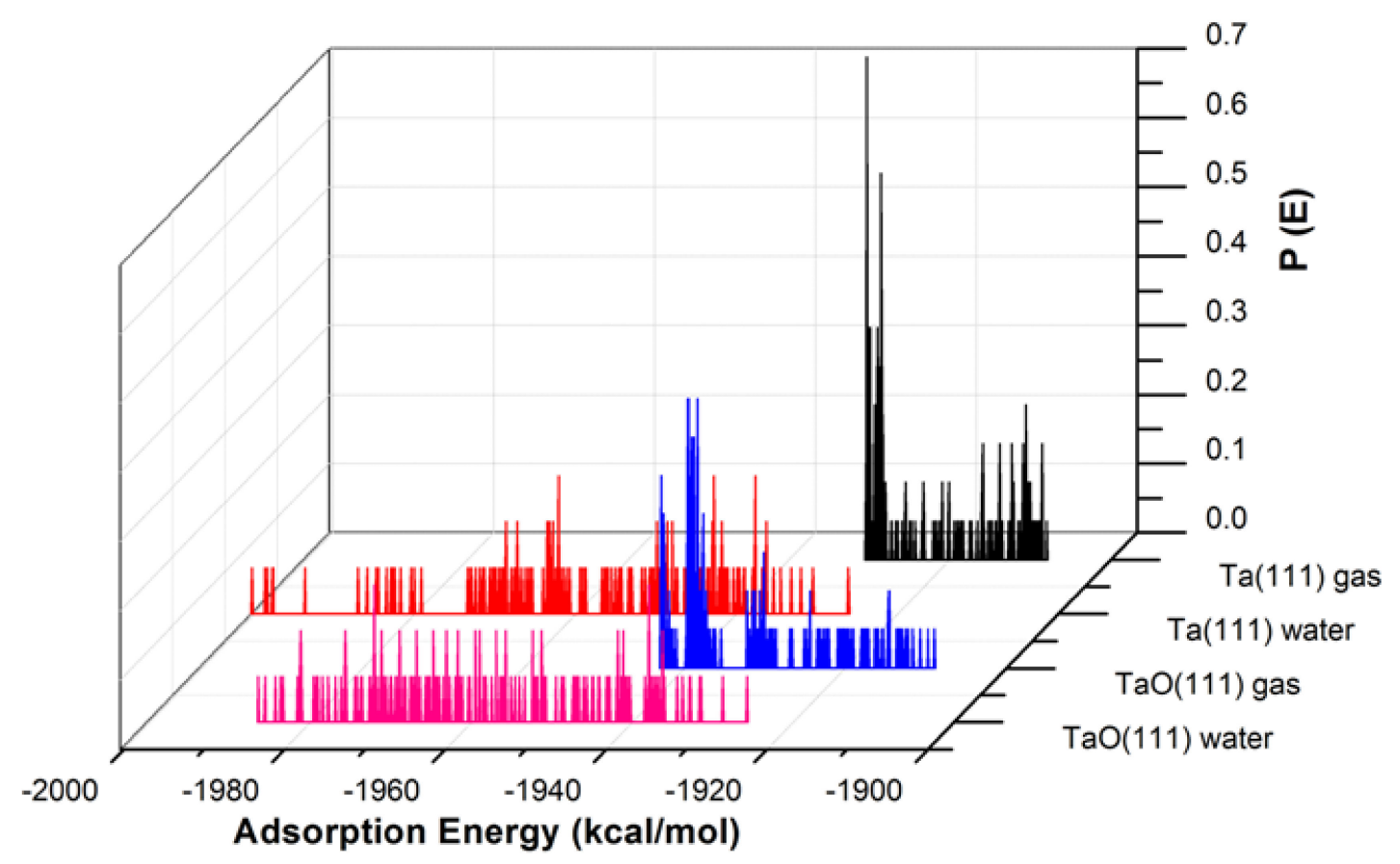

Figure 4. The adsorption energy distribution of the GO-COOH on Ta (111) and $\mathrm{TaO}(111)$ surfaces in the presence and absence of water.

The adsorption energies presented from the MC simulations are summarized in Figure 5. This figure shows the distribution of potential energy as a function of adsorption energy, and the minimum adsorption is located on the left side of the axis. The adsorption energy for $\mathrm{Nb}$ (111) and $\mathrm{Ta}$ (111) surfaces divided per surface area of the used slab models is comparable for both the gas phase and in the presence of water molecules. The presence of water, as expected, favors the adsorption of $\mathrm{GO}-\mathrm{COOH}$, as it decreases the adsorption energy (the energy gain is around $-1.8 \mathrm{kcal} / \mathrm{mol} \cdot \AA 2$ ).

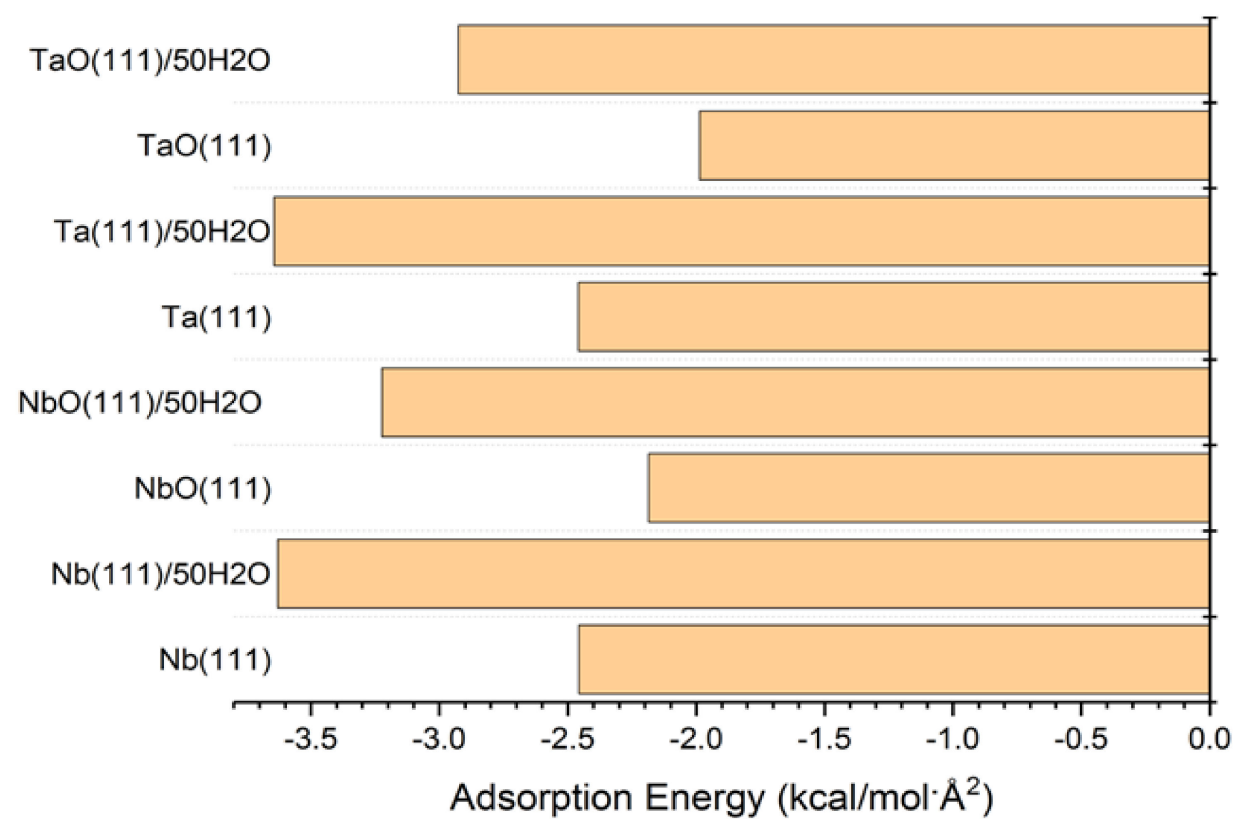

Figure 5. Adsorption energies calculated by the Monte Carlo simulation of GO-COOH on $\mathrm{Nb}$ (111), $\mathrm{NbO}$ (111), $\mathrm{Ta}(111)$ and $\mathrm{TaO}$ (111) surface, in the presence and absence of water. 
The presence of water molecules drastically changes the adsorption geometry of the GO-COOH, Figure 6, top-view. In the absence of water molecules, the distance of GO-COOH ( $\mathrm{H}$ atoms) from the surface plane of the material is around $1.8 \AA$; this distance increases drastically in the presence of water molecules: for the $\mathrm{Nb}(111)$ it is $5.7 \AA$, whereas for Ta (111), it is is $6.4 \AA$. The water molecules are intercalated between the metal (oxide) surface and GO-COOH. These molecules increase the interaction between the two partners and therefore lowers the interaction energy. These water molecules provide common solvation of both partners.
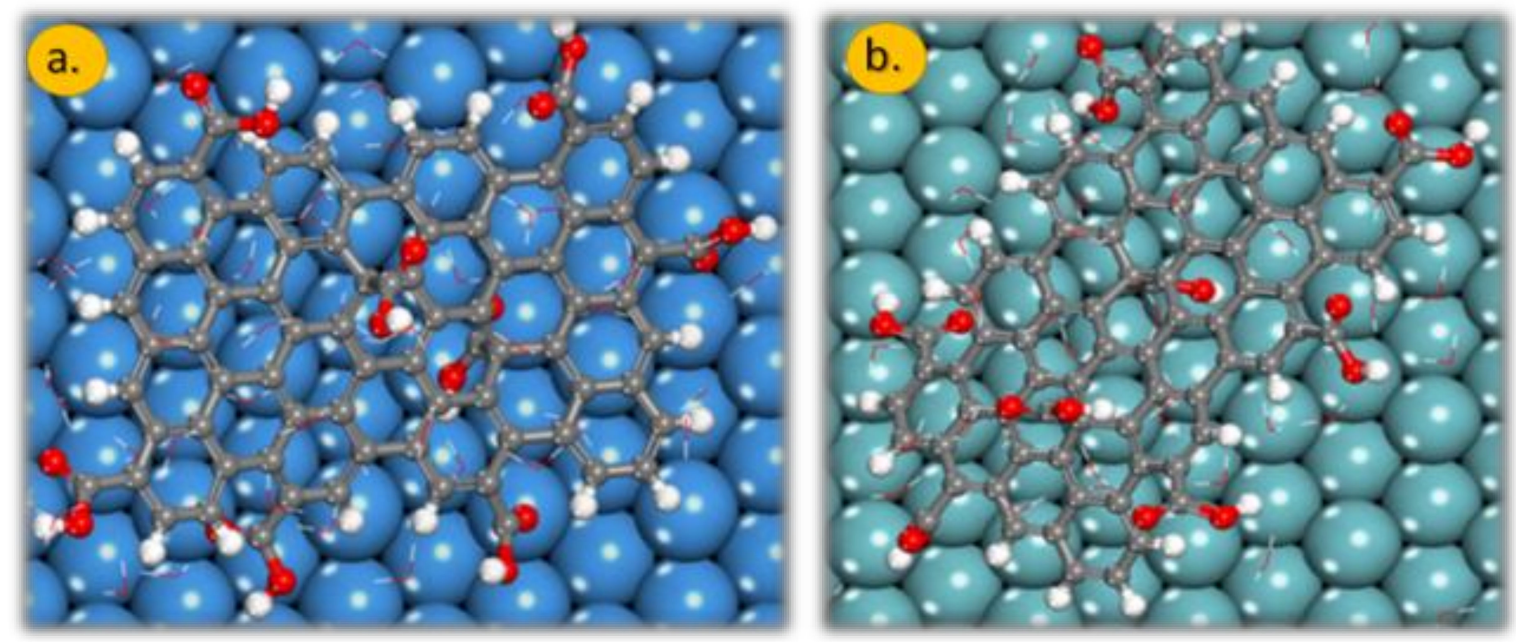

Figure 6. The adsorption geometry of GO-COOH onto the: (a) Ta (111) and (b) $\mathrm{Nb}$ (111) surface in the presence of 50 water molecules. Gray colour: $\mathrm{C}$ atoms, white colour: $\mathrm{H}$ atoms and red colour: $\mathrm{O}$ atoms.

Similarly, the $\mathrm{O}$ atoms of the GO-COOH move further away from the material to host the intercalating water molecules. The $\mathrm{O}$ atoms of the side $\mathrm{GO}-\mathrm{COOH}$ are closer to the surface of the metal. Energies are lower than for the metal counterpart surfaces, both in the gas phase and in the presence of water molecules. This is related to the increased $\mathrm{GO}-\mathrm{COOH}$ atom distances from the oxide surfaces with regard to metal ones (Table 2).

Table 2. Adsorption distances for GO-COOH onto $\mathrm{Nb}$ (111), $\mathrm{NbO}$ (111), $\mathrm{Ta}$ (111) and $\mathrm{TaO}$ (111) surfaces in the absence and presence of 50 water molecules.

\begin{tabular}{|c|c|c|c|c|c|c|c|}
\hline $\begin{array}{c}\text { Substrate } \\
(\text { POS = Plane of Substrate })\end{array}$ & 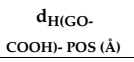 & $\begin{array}{c}\mathrm{d}_{\mathrm{O}(\mathrm{GO}-} \\
\mathrm{COOH})-\mathrm{POS}(\tilde{\mathrm{A}})\end{array}$ & 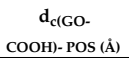 & $\begin{array}{c}\mathrm{d}_{\mathrm{H}(\mathrm{GO}-} \\
\mathrm{COOH})-\mathrm{POS}\left(50 \mathrm{H}_{2} \mathrm{O}\right)(\AA)\end{array}$ & $\begin{array}{c}\mathrm{d}_{\mathrm{O}(\mathrm{GO}-} \\
\mathrm{COOH})-\mathrm{POS}\left(50 \mathrm{H}_{2} \mathrm{O}\right)(\AA)\end{array}$ & $\begin{array}{c}\mathrm{d}_{\text {centroid(GO- }} \\
\text { COOH)- } \operatorname{POS}\left(50 \mathrm{H}_{2} \mathrm{O}\right)(\mathrm{A})\end{array}$ & $\begin{array}{c}\text { Ads. } \\
\text { Geometry }\end{array}$ \\
\hline $\mathrm{Nb}_{\left(\mathrm{H}_{2} \mathrm{O}\right)} 111$ & 5.722 & 6.697 & 6.947 & 1.705 & 2.262 & 8.727 & Planar \\
\hline $\mathrm{NbO}_{\text {(gas) }} 111$ & 2.132 & 1.716 & 1.419 & - & - & 4.345 & Planar \\
\hline $\mathrm{Ta}_{(\text {gas) }} 111$ & 1.818 & 1.533 & 2.285 & - & - & 4.342 & Planar \\
\hline $\mathrm{Ta}_{\left(\mathrm{H}_{2} \mathrm{O}\right)} 111$ & 6.419 & 5.689 & 6.621 & 2.419 & 2.651 & 10.607 & Side \\
\hline $\mathrm{TaO}_{\text {(gas) }} 111$ & 0.841 & 0.758 & 1.261 & - & - & 3.305 & Side \\
\hline $\mathrm{TaO}_{\left(\mathrm{H}_{2} \mathrm{O}\right)} 111$ & 2.122 & 2.156 & 2.981 & 2.244 & 2.648 & 7.988 & Side \\
\hline
\end{tabular}

The GO-COOH on the Ta $(111) / 50 \mathrm{H}_{2} \mathrm{O}$ is adsorbed on the side, whereas in the case of $\mathrm{Nb}$ (111) $/ 50 \mathrm{H}_{2} \mathrm{O}$, we observe a different adsorption geometry-the planar one. This is in good agreement with the experimental data obtained concerning the corrosion inhibition efficiency difference between $\mathrm{Nb}$ and $\mathrm{Ta}$ (the planar adsorption of GO-COOH covers a greater surface compared with the side adsorption geometry). The evaluation of the adsorption of oxides is important in the case of initial surface corrosion but also for non-uniform corrosion although we have not tested the inhibition efficiency for the $\mathrm{Ta}$ and $\mathrm{Nb}$ oxides. 


\subsection{Molecular Dynamics}

The MD snapshots of GO-COOH adsorbed onto the Ta and $\mathrm{TaO}$ (111) surfaces with the upright direction at different simulation times are displayed in Figures 7 and 8.

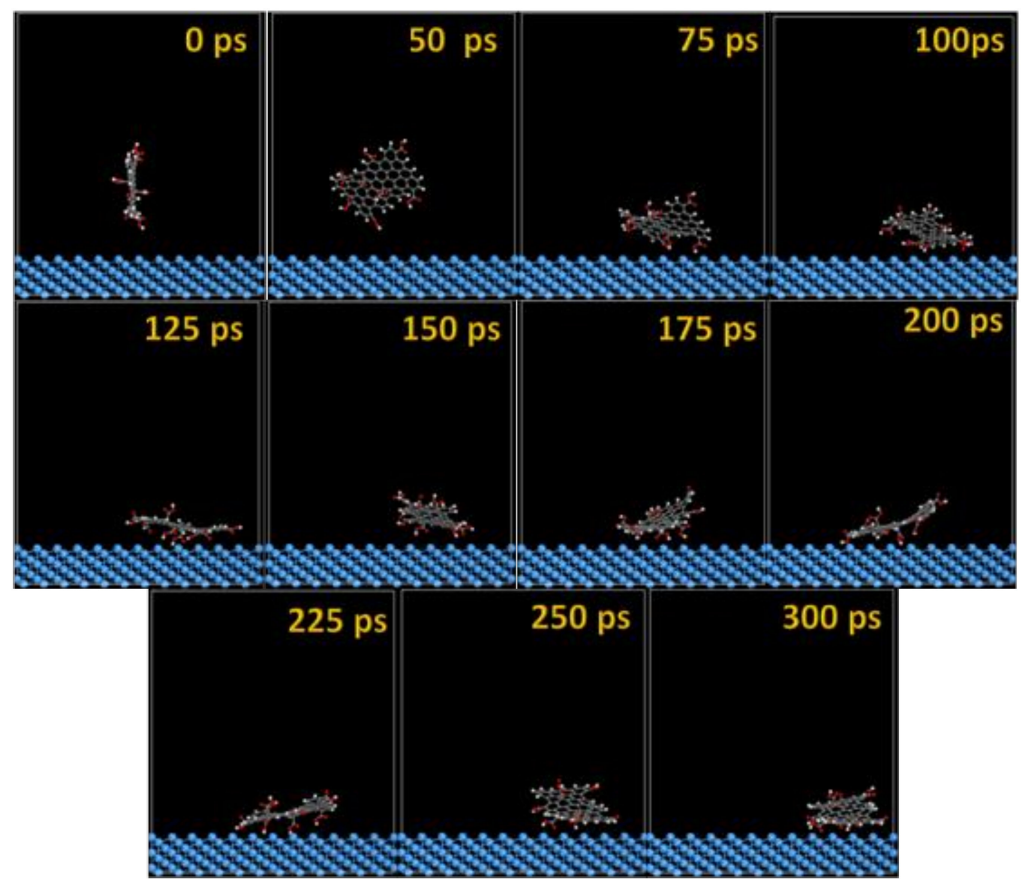

Figure 7. Time sequence interaction poses of the GO-COOH adsorbed on the Ta (111) surface.

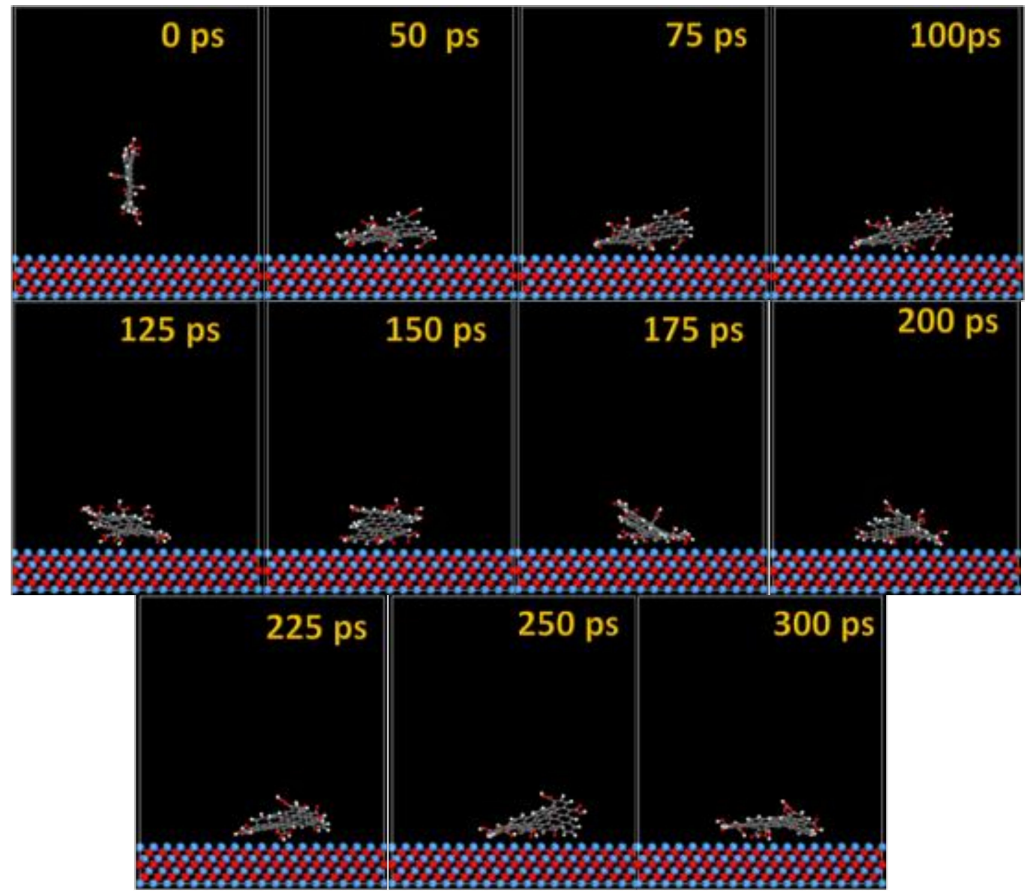

Figure 8. Time sequence interaction poses of the GO-COOH adsorbed on the $\mathrm{TaO}(111)$ surface.

After several ps of simulation time, on both of the surfaces (Ta and $\mathrm{TaO}$ ), the GO-COOH has a tendency for surface interaction. The interaction with the TaO surface appears to progress slightly faster than with the Ta surface (GO-COOH that sits on the surface after $70 \mathrm{ps}$ ); in this case after 45 ps 
of the simulation time, GO-COOH sits flat on the surface, reaching the lowest energy conformation on surfaces takes some hundreds ps after which there is a tendency for the GO-COOH to adsorb closest to the surface.

From Figure 9, the nearest distance distribution for most of the $\mathrm{C}(\mathrm{GO}-\mathrm{COOH})-\mathrm{Ta}$ (surface) atoms during the 300 ps MD simulation time has a very minor contribution at $1.03 \AA$, and a major one at the side $-\mathrm{COOH}$ group at $2.89 \AA$. Most of the atoms from the top $\mathrm{COOH}$ group during MS pass time at $2.88 \AA$; for the two $\mathrm{COOH}$ groups, there is a small RDF at a distance $2.86 \AA$ that arises during the $\mathrm{GO}-\mathrm{COOH}$ interaction with the surface in the interface vicinity.

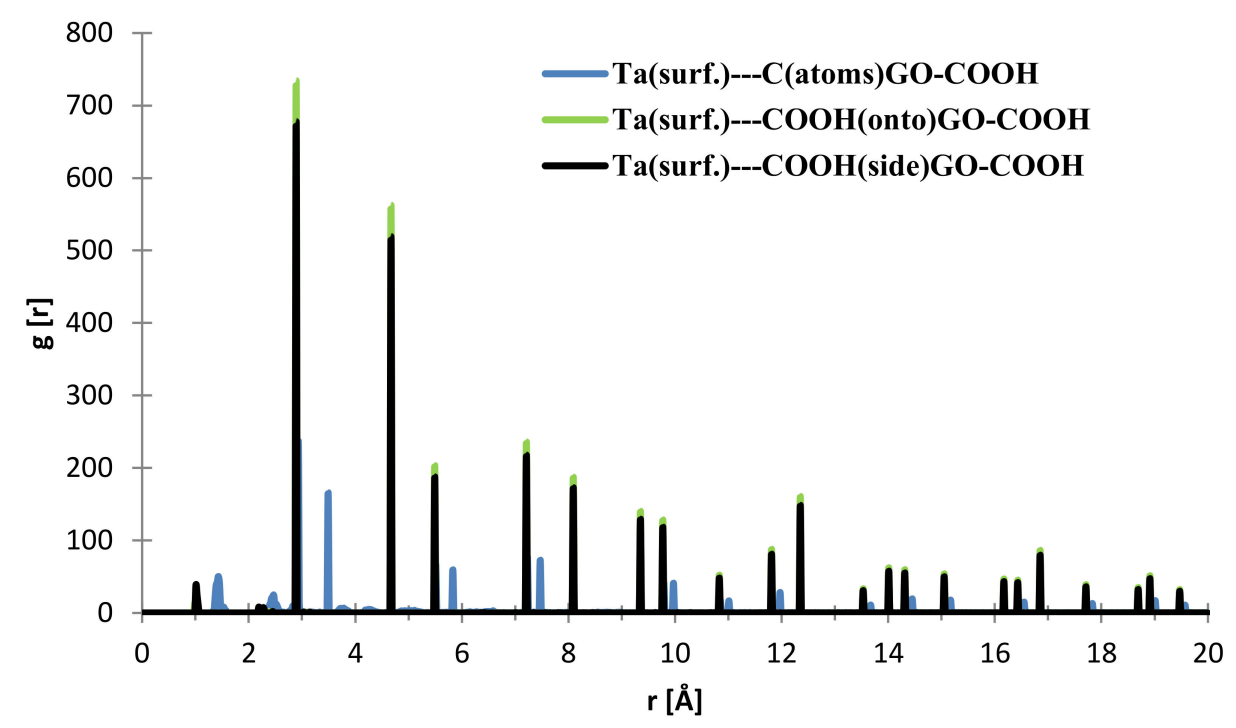

Figure 9. RDFs between different GO-COOH atoms: tantalum (111) surface atoms.

In the case of the interface distances for the $\mathrm{NbO}(111)$ surface as seen from Figure 10, the $\mathrm{C}$ (from GO-COOH) is positioned at $1.45 \AA$ (small contribution) and at $2.15 \AA$, the top-COOH group at $1.04 \AA$ (minor contribution), $2.16 \AA$ and the side $\mathrm{COOH}$ group is positioned at $2.13 \AA$.

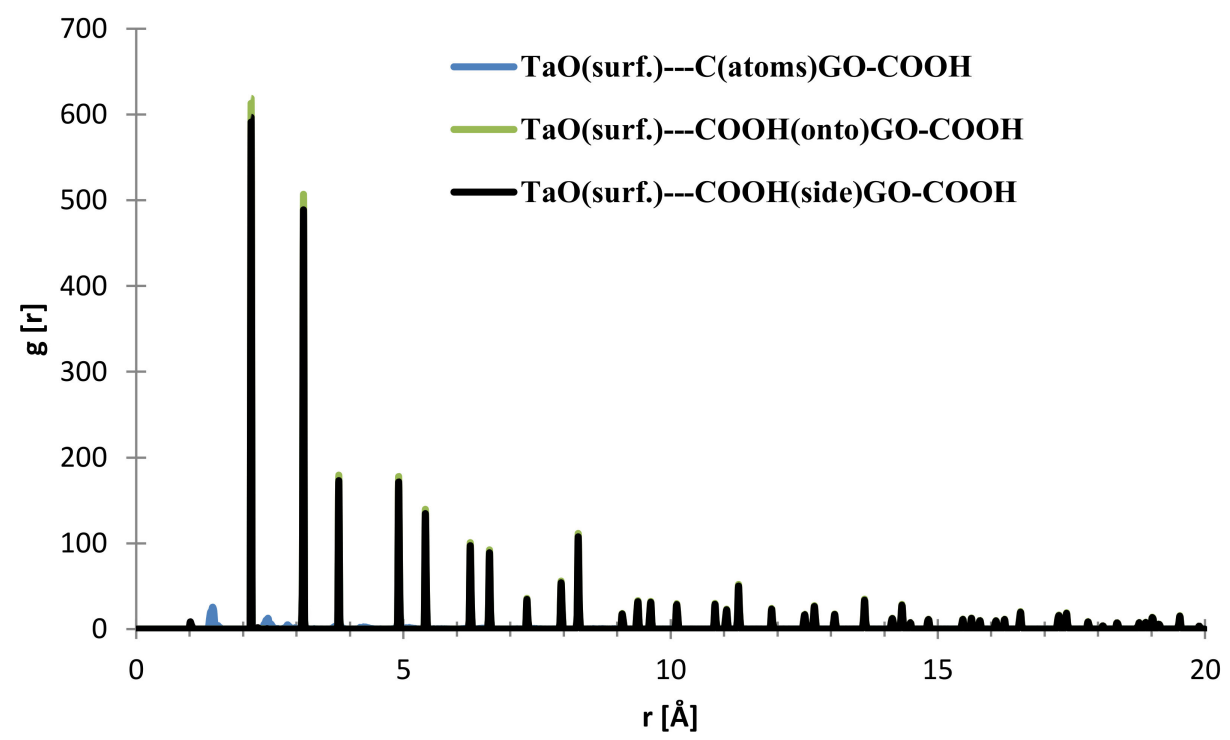

Figure 10. RDFs between different GO-COOH atoms: tantalum (111) surface atoms.

The MD adsorption snapshots of GO-COOH on $\mathrm{Nb}$ and $\mathrm{NbO}$ (111) (Figures 11 and 12) surfaces are similar to those of Ta and TaO. 


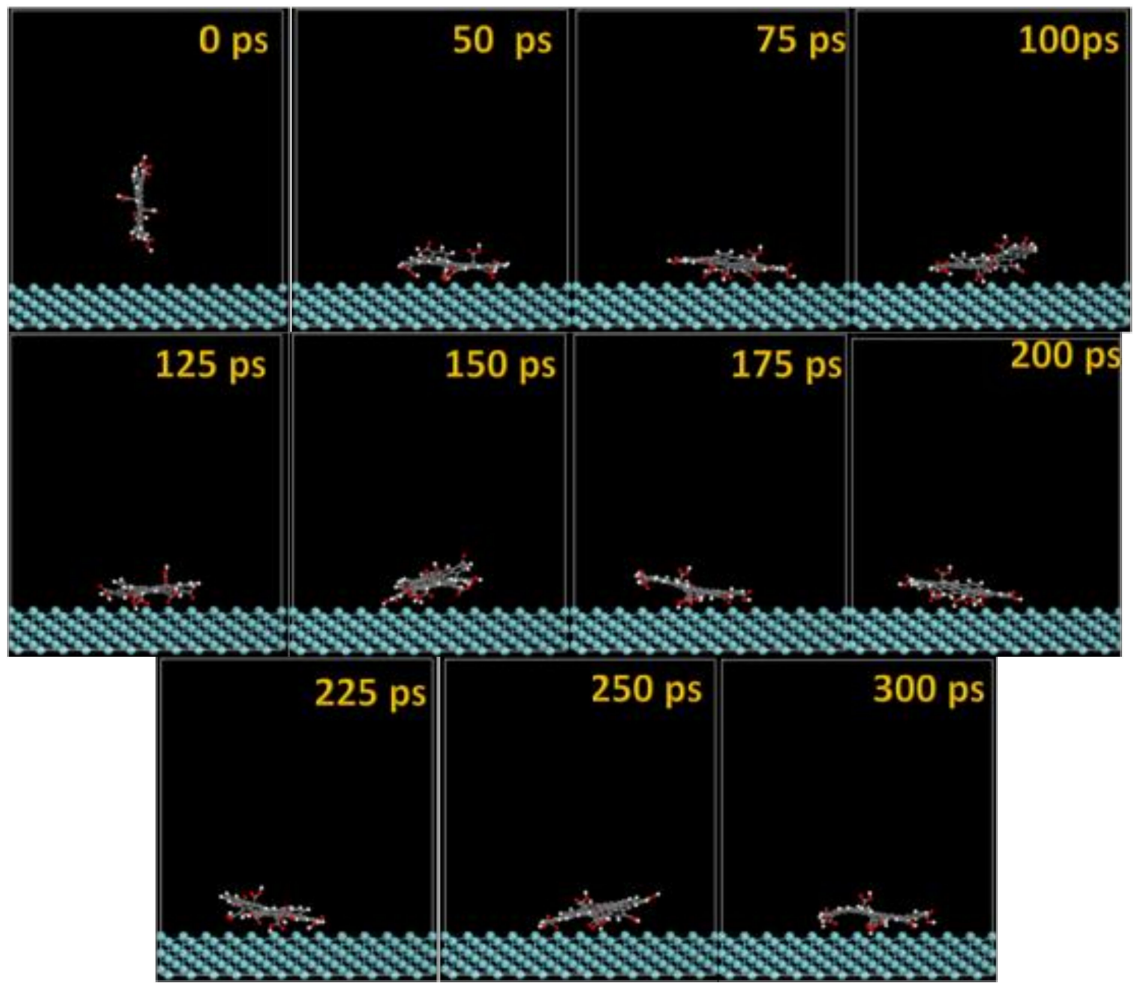

Figure 11. Time sequence interaction poses of the GO-COOH adsorbed on the $\mathrm{Nb}(111)$ surface.

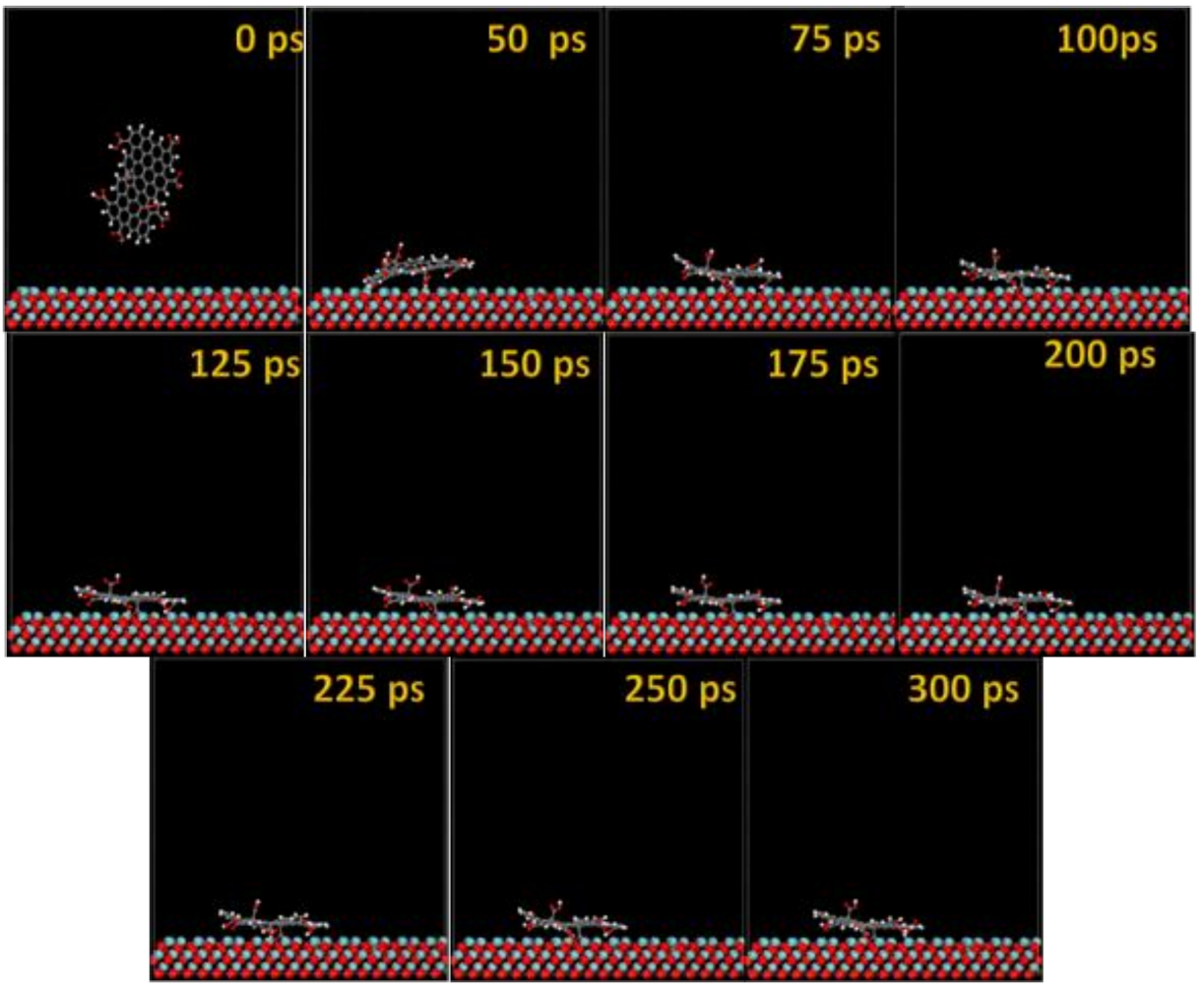

Figure 12. Time sequence interaction poses of the $\mathrm{GO}-\mathrm{COOH}$ adsorbed on the $\mathrm{NbO}(111)$ surface.

The GO-COOH rapidly reaches the surfaces; after 45 ps, it lies flat on the surfaces and tends to find the most favorable adsorption geometry that leads to the lowest energy of the systems. 
To evaluate the interaction, RDF calculations involving the surface atoms of slab models and the GO-COOH molecule were analyzed. In Figure 13, the nearest distance distribution for most of the C (GO-COOH)-Nb (surface) atoms during the 300 ps MD simulation time is at $1.41 \AA$, the side $-\mathrm{COOH}$ group has major distance distributions at 2.84 and $3.45 \AA$, whereas most of the atoms from the top $\mathrm{COOH}$ group during MS spend time at $2.83 \AA$, for the two $\mathrm{COOH}$ groups, there is a small RDF at a very short distance of $1.1 \AA$ that arises during the GO-COOH contact with the surface and its folding at the contact interface. The small distributions at high $r$ values above $5 \AA$ arise from the fact that the MD is started at a distance $20 \AA$ from the surface.

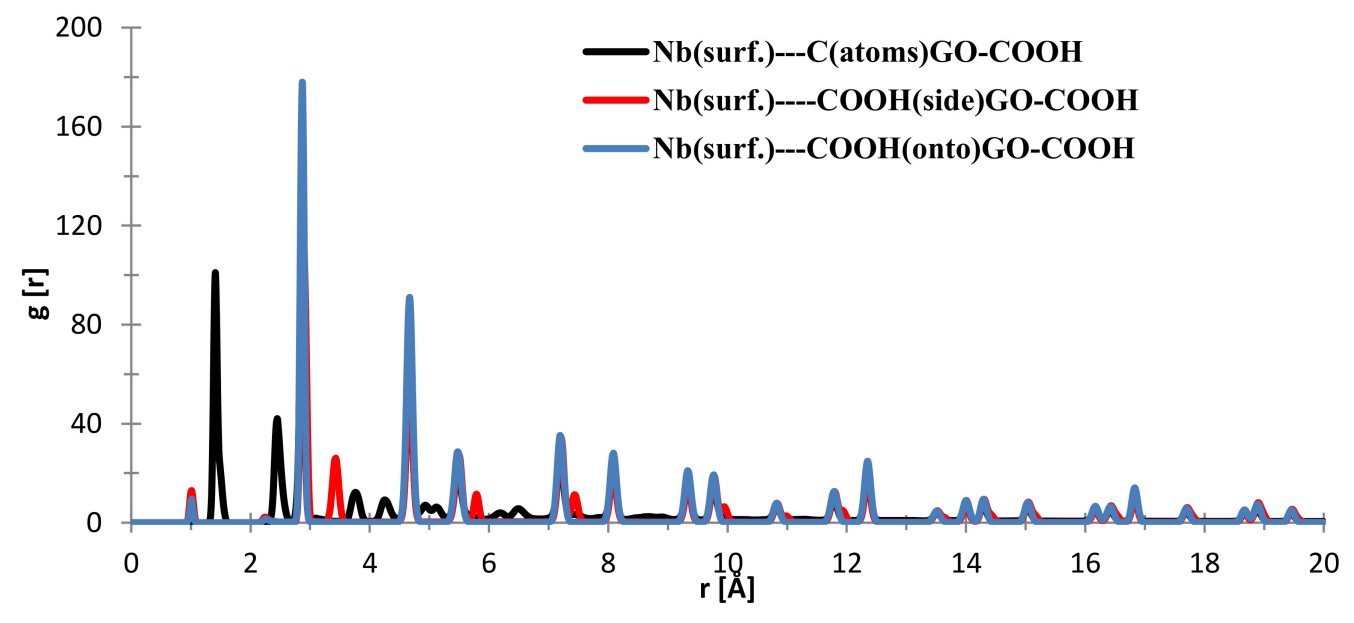

Figure 13. RDFs between different GO-COOH atoms: niobium (111) surface atoms.

Regarding the interface distances in the case of $\mathrm{NbO}(111)$, as seen from Figure 14, the $\mathrm{C}$ (from GO-COOH) is positioned at 1.85-1.95 $\AA$ (two RDF peaks), the side-COOH group at $1.1 \AA$ (important contribution) and the top $\mathrm{COOH}$ group fluctuates at 1.94 and 2.97 (meaning that the search for the most stable position has more complex dynamics than in the case of the $\mathrm{Nb}$ surface; this is also evidenced by the RDF spikes with decreased intensity from 20 to $4 \AA$ ).

In general, these short distances lead to relatively strong interactions of GO-COOH with $\mathrm{Ta}, \mathrm{Nb}$, and $\mathrm{TaO}, \mathrm{NbO}$ surfaces. The calculated adsorption energies for the MD systems are, as in the case of $\mathrm{MC}$ calculations, very similar for both of the systems. In the case of $\mathrm{Nb}(111)$, the adsorption energy is $-0.380 \mathrm{kcal} / \mathrm{mol} \cdot \AA 22$, whereas for the Ta (111) surface, this value is $-0.382 \mathrm{kcal} / \mathrm{mol} \cdot \AA 2$.

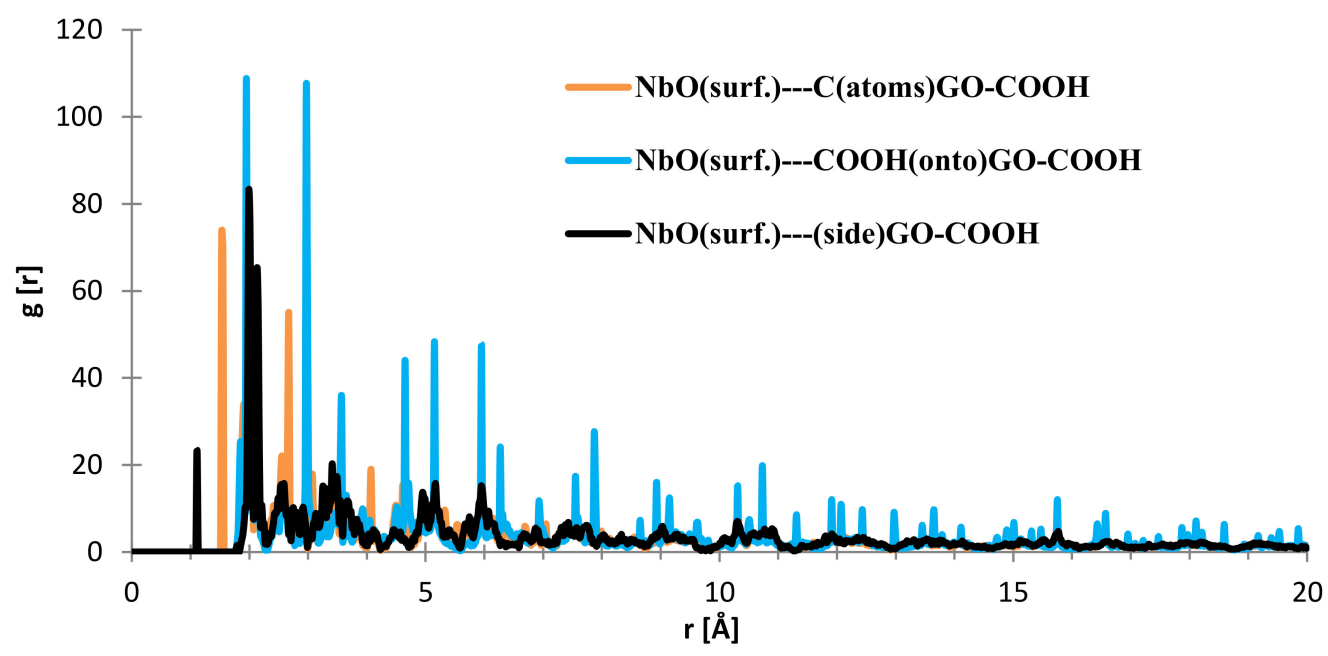

Figure 14. RDFs between different GO-COOH atoms: $\mathrm{NbO}(111)$ surface atoms. 


\section{Conclusions}

This work describes the corrosion inhibition of niobium and tantalum by modified graphene oxide. Experimental results from potenciodynamic measurements will be subjected to theoretical calculations.

The results of the inhibition efficiency showed that the use of $\mathrm{GO}-\mathrm{COOH}$ for corrosion inhibition in the aqueous acidic media, in the case of $\mathrm{Nb}$, can decrease the corrosion by up to $70 \%$, whereas for the Ta, the inhibition efficiency reaches $60 \%$. These data are important as a starting point to see if the MC and MD simulations will be in agreement and offer some insights regarding the molecular behavior of GO-COOH at the studied material interface. Thus, the interaction of GO-COOH on the $\mathrm{Nb}$ (111), $\mathrm{NbO}$ (111), Ta (111) and TaO (111) surfaces was investigated by MC and MD simulations with the aim to better understand the interface interaction of $\mathrm{GO}-\mathrm{COOH}$. The $\mathrm{MC}$ simulations are in agreement with the experimentally observed behavior of $\mathrm{GO}-\mathrm{COOH}$; the calculated interaction energy was a bit stronger between the $\mathrm{Nb}(111) / 50 \mathrm{H} 2 \mathrm{O} / / \mathrm{GO}-\mathrm{COOH}$ than the $\mathrm{Ta}(111) / 50 \mathrm{H} 2 \mathrm{O} / / \mathrm{GO}-\mathrm{COOH}$. The MD and MC simulation can be helpful to design and explore GO structures prior to experimental measurements that tend to exhibit more pronounced inhibition efficiencies, leading to decreased corrosion cost.

Author Contributions: F.P. conceived and designed the experiments; V.M. performed the experiments; V.M. and F.P. analyzed the data; V.M. contributed reagents/materials/analysis tools; F.P. wrote the paper.

Funding: This research received no external funding.

Acknowledgments: V.M. is grateful to the Austrian Agency for International Cooperation in Education \& Research (OeAD-GmbH), Centre for International Cooperation \& Mobility (ICM) for awarding a CEEPUS-scholarship (Zl.: ICM-2015-01825). The authors gratefully acknowledge the support from the Ministry of Education, Science and Technology of Kosovo (Nr.2-5069) for providing them with the computing resources.

Conflicts of Interest: The authors declare no conflict of interest.

\section{References}

1. Plankaert, R. Surface Coating in Ullmann's Encyclopedia of Industrial Chemistry, 5th ed.; VCH: Weinheim, Germany, 1994; p. 170.

2. Lagrenée, M.; Mernari, B.; Bouanis, M.; Traisnel, M.; Bentiss, F. Study of the mechanism and inhibiting efficiency of 3,5-bis(4-methylthiophenyl)-4H-1,2,4-triazole on mild steel corrosion in acidic media. Corr. Sci. 2002, 44, 573-588. [CrossRef]

3. Raja, P.B.; Sethuraman, M.G. Natural products as corrosion inhibitor for metals in corrosive media-A review. Mater. Lett. 2008, 62, 113-116. [CrossRef]

4. Trabanelli, G. Inhibitors-An old remedy for a new challenge. Corrosion 1991, 47, 410-419. [CrossRef]

5. Van Alsten, J.G. Self-assembled monolayers on engineering metals: structure, derivatization, and utility. Langmuir 1999, 15, 7605-76014. [CrossRef]

6. Gunasekaran, G.; Natarajan, R.; Muralidharan, V.S.; Palaniswamy, N.; Appa Rao, B.V. Inhibition by phosphonic acids-An overview. Anti-Corrosion. Methods Mater. 1997, 44, 248-259. [CrossRef]

7. Bélanger, D.; Pinson, J. Electrografting: A powerful method for surface modification. Chem. Soc. Rev. 2011, 40, 3995-4048. [CrossRef] [PubMed]

8. Cao, G.; Wang, Y. Nanostructures and Nanomaterials; World Scientific: Jurong East, Singapore, 2011; p. 232. ISBN 978-981-4322-50-8.

9. Das, S.; Mitra, S.; Khurana, S.M.P.; Debnath, N. Nanomaterials for biomedical applications. Front. Life Sci. 2013, 7, 90-98. [CrossRef]

10. Bai, Y.; Filippo, M.-S.; Angelis, D.; Bisquert, J.; Wang, P. Titanium dioxide nanomaterials for photovoltaic applications. Chem. Rev. 2014, 114, 10095-10130. [CrossRef] [PubMed]

11. Ghiamati Yazdi, E.; Ghahfarokhi, Z.S.; Bagherzadeh, M. Protection of carbon steel corrosion in $3.5 \% \mathrm{NaCl}$ medium by aryldiazonium grafted graphene coatings. New J. Chem. 2017, 41, 12470-12480. [CrossRef]

12. Chang, C.-H.; Huang, T.-C.; Peng, C.-W.; Yeh, T.-C.; Lu, H.-I.; Hung, W.-I.; Weng, C.-J.; Yang, T.-I.; Yeh, J.-M. Novel anticorrosion coatings prepared from polyaniline/graphene composites. Carbon 2012, 50, 5044-5051. [CrossRef] 
13. Prasai, D.; Tuberquia, J.C.; Harl, R.R.; Jennings, G.K.; Bolotin, K.I.; Bolotin, K.I. Graphene: Corrosion-inhibiting coating. ACS Nano 2012, 6, 1102-1108. [CrossRef] [PubMed]

14. Yu, H.; Zhang, B.; Bulin, C.; Li, R.; Xing, R. High-efficient synthesis of graphene oxide based on improved hummers method. Sci. Rep. 2016, 6, 36143. [CrossRef] [PubMed]

15. Lee, S.; Eom, S.H.; Chung, J.S.; Hur, S.H. Large-scale production of high-quality reduced graphene oxide. Chem. Eng. J. 2013, 233, 297-304. [CrossRef]

16. Ye, R.; Xiang, C.; Lin, J.; Peng, Z.; Huang, K.; Yan, Z.; Cook, N.P.; Samuel, E.L.G.; Hwang, C.-C.; Ruan, G.; et al. Coal as an abundant source of graphene quantum dots. Nat. Commun. 2013, 4, 2934. [CrossRef] [PubMed]

17. Gomez, B.; Likhanova, N.V.; Dominguez-Aguilar, M.A.; Martinez-Palou, R.; Vela, A.; Gazquez, J.L. Quantum chemical study of the inhibitive properties of 2-pyridyl-azoles. J. Phys. Chem. B 2006, 110, 8928-8934. [CrossRef] [PubMed]

18. Khaled, K.F. Molecular simulation, quantum chemical calculations and electrochemical studies for inhibition of mild steel by triazoles. Electrochim. Acta 2008, 53, 3484-3492. [CrossRef]

19. Khalil, N. Quantum chemical approach of corrosion inhibition. Electrochim. Acta 2003, 48, 2635-2640. [CrossRef]

20. Khaled, K.F.; Amin, M.A. Computational and electrochemical investigation for corrosion inhibition of nickel in molar nitric acid by piperidines. J. Appl. Electrochem. 2008, 38, 1609-1629. [CrossRef]

21. Obot, I.B.; Obi-Egbedi, N.O. Theoretical study of benzimidazole and its derivatives and their potential activity as corrosion inhibitors. Corros. Sci. 2010, 52, 657-660. [CrossRef]

22. Tang, Y.M.; Yang, W.Z.; Yin, X.S.; Liu, Y.; Wang, R.; Wang, J.T. Phenyl-substituted amino thiadiazoles as corrosion inhibitors for copper in 0.5 M H2SO4. Mater. Chem. Phys. 2009, 116, 479-483. [CrossRef]

23. Saha, S.K.; Dutta, A.; Ghosh, P.; Sukul, D.; Banerjee, P. Novel Schiff base molecules as efficient corrosion inhibitors for mild steel surface in $1 \mathrm{M} \mathrm{HCl}$ medium: Experimental and theoretical approach. Phys. Chem. Chem. Phys. 2006, 18, 17898-17911. [CrossRef] [PubMed]

24. Nwankwo, H.U.; Olasunkanmi, L.O.; Ebenso, E.E. Experimental, quantum chemical and molecular dynamic simulations studies on the corrosion inhibition of mild steel by some carbazole derivatives. Sci. Rep. 2017, 7, 2436. [CrossRef] [PubMed]

25. Jihong, W.; Ying, D.; Yan, W.; Qing, L.; Hongyan, W.; Qing, W. Adsorption of graphene on an $\mathrm{Fe}_{3} \mathrm{O}_{4}$ surface: A molecular dynamics simulation study. J. Adhes. 2018, 94, 238-253. [CrossRef]

26. Mehmeti, V.V.; Berisha, A.R. Corrosion Study of Mild Steel in Aqueous Sulfuric Acid Solution Using 4-Methyl-4H-1,2,4-Triazole-3-Thiol and 2-Mercaptonicotinic Acid-An Experimental and Theoretical Study. Front. Chem. 2017, 5, 61. [CrossRef] [PubMed]

27. Ding, H.; Shen, X.; Chen, C.; Zhang, X. Molecular dynamics simulations of simple aromatic compounds adsorption on single-walled carbon nanotubes. RSC Adv. 2016, 6, 80972-80980. [CrossRef]

28. Shtogun, Y.V.; Woods, L.M.; Dovbeshko, G.I. Adsorption of Adenine and Thymine and Their Radicals on Single-Wall Carbon Nanotubes. J. Phys. Chem. C 2007, 111, 18174-18181. [CrossRef]

29. Pourbaix, M. Atlas of Electrochemical Equilibria in Aqueous Solutions; Pergamon Press: New York, NY, USA, 1966.

30. Asselin, E.; Ahmed, T.M.; Alfantazi, A. Corrosion of niobium in sulphuric and hydrochloric acid solutions at 75 and $95^{\circ}$ C. Corrs. Sci. 2007, 49, 694-710. [CrossRef]

31. De Souza, K.A.; Robin, A. Electrochemical behavior of Titanum-Tantalum alloys in sulfuric acid solutions. Mater. Corros. 2004, 55, 853-860. [CrossRef]

32. Pan, T.J.; Chen, Y.; Zhang, B.; Hu, J.; Li, C. Corrosion behavior of Niobium coated 304 stainless steel in acid solution. Appl. Surf. Sci. 2016, 369, 320-325. [CrossRef]

33. Bagherzadeh, M.; Ghahfarokhi, Z.S.; Yazdi, E.G. Electrochemical and surface evaluation of the anticorrosion properties of reduced graphene oxide. RSC Adv. 2016, 6, 22007-22015. [CrossRef]

(C) 2018 by the authors. Licensee MDPI, Basel, Switzerland. This article is an open access article distributed under the terms and conditions of the Creative Commons Attribution (CC BY) license (http:/ / creativecommons.org/licenses/by/4.0/). 